\title{
LXI. Experiments and observations on the applications of photometry to certain cases connected with the undulatory theory of light
}

\section{J.H. Wheeler Esq.}

To cite this article: J.H. Wheeler Esq. (1834) LXI. Experiments and observations on the applications of photometry to certain cases connected with the undulatory theory of light, Philosophical Magazine Series 3, 5:30, 439-444, DOI: 10.1080/14786443408648501

To link to this article: http://dx.doi.org/10.1080/14786443408648501

曲 Published online: 01 Jun 2009.

Submit your article to this journal $[\pi$

Џ Article views: 3

View related articles 
was also definite in its magnetic action (366. 367. 376. 377.); and, though this result was not pursued to any extent, I have no doubt that the success which has attended the development of the chemical effects is not more than would accompany an investigation of the magnetic phænomena.

Royal Institution, Dec. 31, 1833.

LXI. Experiments and Observations on the Application of Photometry to certain Cases connected with the Undulatory Theory of Light. By J. H. WhEELER, Esq.*

THE interest inspired by the discussions which have arisen within the last few years on the relative claims of the corpuscular and undulatory theories of light, has been productive of inestimable benefit to science. To Mr. R. Potter the scientific world is certainly indebted for bringing forward the first formidable objections, grounded on the application of mathematical reasoning, to highly original experimental evidence; and whatever opinion may be entertained of the result of the controversy, and the light thrown upon the question by the various replies and rejoinders which have appeared, the excellence of Mr. Potter's experimental labours, and the profound ability with which he has maintained his side in the controversy, cannot be too highly appreciated. And it eminently deserves to be remembered, that with the most perfectly philosophic love of truth, he has in a more recent paper candidly allowed the result of a long and laborious series of experiments to be in favour of the theory he set out by opposing. (See this Journal, November 1833.) Still, however, some of the principal objections brought forward by this gentleman remain unanswered. I allude to those which depend upon the calculated intensities of light in certain cases, which are found totally to disagree with the observed intensities as determined by his highly ingenious and admirably conducted experiments, depending on the application of photometry, which have appeared in several Numbers of this Journal.

Having felt from the first a deep interest in the subject, and especially as connected with photometry, I have ever since the publication of Mr. Potter's experiments been engaged, as much as my other avocations would allow, in attempts to repeat and verify them, and, if possible, to extend their application to other cases. My labours hitherto have met with but limited success, partly from the want of sufficient experimental skill, but chiefly from some apparently insuperable

* Communicated by the Author. 
difficulties in the calculation of the results, which I am obliged to confess I cannot bring into accordance with those of $\mathrm{Mr}$. Potter. My object, then, in the present communication will be to state the results $I$ have arrived at, such as they are, in the hope that they will receive a candid examination. And in order to afford all facilities for tracing out the cause of error wherever it may lie concealed, and disentangling the subject from its perplexities, I will first lay down the simple elementary principles by which I have been guided in my calculations, and which appear to me to involve the correct principies of this branch of optical science.

The fundamental principle on which all photometrical comparisons must proceed is easily seen to be, the equalization of the illuminating effects as estimated by the eye, and the comparison of the distances of the luminous bodies necessary to produce that equalization.

Now the illuminating effect is due jointly to the absolute brightness of the luminous points, and the number of them; or, in other words, the product of the intensity and the quantity of light.

For the same light at different distances $(d)$, the intensity (i) owing to the diffusion of the rays is inversely as $d^{2}$, but at the same time the apparent area into which the rays are condensed diminishes, or the condensation increases, in the same ratio; hence on both considerations the intensity is constant for all distances.

For different lights, the absolute intensity of each being thus constant for all distances, the quantity of light varies with the absolute area (a) directly, and the apparent visual area inversely; thus, for the illuminating effect (I), we shall have

$$
\mathrm{I}=\frac{i a}{d^{2}}
$$

If we are examining the light reflected from a given surface inclined to the direction of vision, it will be easily seen that the inclination is the complement of the angle of reflection $(\phi)$, and that instead of the absolute area $(a)$ we must take for the effective area $a \cdot \cos \phi$, or the illuminating effect will be

$$
\mathrm{I}=\frac{i \cdot a \cdot \cos \phi}{d^{2}}
$$

And in comparing two lights, we shall have as a general formula, to be modified to suit the particular cases which may arise, (accenting the letters for the second light,)

$$
\frac{\mathrm{I}}{\mathbf{I}^{\mathrm{N}}}=\frac{i \cdot a \cdot \cos \phi d^{\prime z}}{i^{\prime} \cdot a^{\prime} \cdot \cos \phi^{\prime} d^{z}} \text {. }
$$


My first object was the comparison of the illumination in the dark and bright parts of Newton's rings as in Mr. Potter's experiments ; but here there are several difficulties of no small magnitude to be encountered: first, we must suppose equal portions of each dark and bright space, isolated so as to become the fair objects of comparison for the intensity of light they respectively give. In the next place, there is the radical difficulty in using the apparatus which Mr. Potter so candidly allows, which arises from the necessity for transferring the eye from the inclined glasses to the rings alternately. For all these difficulties, indeed, as Mr. Potter has justly observed, there is no remedy but steady and repeated practice. By this means, but certainly by no other, can the eye become suffciently accustomed to the work to be able to form an unhesitating decision, and to give confident approximations, at least, to correct comparisons. After a tolerably long experience in this sort of experiment, I must candidly own that I have never been able to feel that entire and perfect confidence in such determinations which would suffice for resting upon them any very nice and delicate conclusions. Yet $\mathrm{I}$ agree with Mr. Potter, that long practice will enable us to attain a degree of precision which at first sight would have appeared hopeless.

I will not, however, dwell upon these points, but proceed at once to detail my experiments, in which, with every degree of care and caution, I have, owing to some cause at present quite inexplicable to me, arrived at results very different from those of Mr. Potter.

It will not be necessary for me to detail the construction of my apparatus, because it was in every point precisely the same as Mr. Potter's, for which I would refer the reader to his paper in this Journal, September 1832, [Lond. and Edinb. Phil. Mag. vol.i.] p. 174. I will simply proceed to give the results of my experiments.

In this case the absolute areas of the two portions of inclined glasses are the same, or (using the accented letters to apply to the second glass) $a=a^{\prime}$, and consequently by the foregoing principles, we shall have (since $d=d^{\prime}$ )

$$
\mathrm{I} \mathrm{I}^{\prime}=\frac{i \cos \phi}{i^{\prime} \cos \phi^{\prime}},
$$

In order to find $i$ and $i^{\prime}$ I have adopted Mr. Potter's valuable and curious formula for glass, which is, in fact, the basis of all his calculations of these experiments; and I thus find the following results, which will be best stated in a tabular form.

Third Series. Vol. 5. No. 30. Dec. 1834. $\quad 3 \mathrm{~L}$ 


\begin{tabular}{|c|c|c|}
\hline \multicolumn{3}{|c|}{ Homogeneous Red Light. } \\
\hline $\begin{array}{c}\text { Glass for the } \\
\text { Dark Ring. } \\
\text { Incidence. }\end{array}$ & $\begin{array}{c}\text { Glass for e } \\
\text { Light Ring. } \\
\text { Incidence. }\end{array}$ & $\begin{array}{c}\text { Ratio } \frac{{ }^{\mathrm{I}}}{\mathrm{I}^{\prime}} \\
\text { by Formula above. }\end{array}$ \\
\hline $30^{\circ}$ & $70^{\circ}$ & 1.267 \\
30 & $7 \mathrm{I}$ & 1.25 \\
40 & 73 & $1 \cdot 33$ \\
40 & 74 & $1 \cdot 33$ \\
\hline
\end{tabular}

The results in this last column differ so widely from $\mathrm{Mr}$. Potter's, that I was led to examine several times over the whole calculation; but have been able to detect nothing which can have led to error. I can therefore merely give my results as they stand, and those interested in the subject may possibly be able to throw some light upon the point by further examination.

I will only add, that with regard to the undulatory theory, Mr. Potter's calculation of the ratio of illumination from that theory, viz. $1 \cdot 1538$, approaches so much more nearly to agreement with my results than he found it to do with his, that perhaps we shall find the error (as there must be one somewhere) will in time show that there is in reality a still more close accordance between theory and experiment. Indeed, I will add that as Mr. Potter's calculation is founded upon his estimate of $\frac{1}{30}$ th of the incident light being reflected from glass, so from some trials of my own, (which I do not doubt are of far inferior accuracy,) I found the proportion more nearly $\frac{1}{2}-t$ th. Now this was quite independent of the last experiments. And it is curious, that on calculation with this number, in the way adopted by Mr. Potter, I find the resulting ratio from theory about $1 \cdot 25$, which accords exactly with these experiments.

I made other sets of experiments, as Mr. Potter did, to compare the illumination from reflection at the surfaces of several different substances, with the view of comparing the results with the expression for such illumination derived from the undulatory theory.

In the first instance I compared the effects of crown glass and of a diamond possessing a tolerably good plane surface, to the area of which that of the glass was carefully equalized: we have then to find $i^{\prime}$ (for glass), as before, by Mr. Potter's formula, and since we here equalize the lights, or make $\mathrm{I}=\mathrm{I}^{\prime}$, we have for diamond $i=i^{\prime} \frac{\cos \phi^{\prime}}{\cos \phi}$. 
to the Undulatory Theory of Light.

The following are the results:

\begin{tabular}{|c|c|c|}
\hline $\begin{array}{c}\text { Incidence on } \\
\text { Diamond. }\end{array}$ & $\begin{array}{c}\text { Corresponding } \\
\text { Incidence on } \\
\text { Glass. }\end{array}$ & $\begin{array}{c}\text { Ratio of Reflection } \\
\text { by Formula. }\end{array}$ \\
\hline $3^{\circ}$ & $63^{\circ}$ & $20 \cdot 6$ \\
10 & $6348^{\prime}$ & $18 \cdot 8$ \\
30 & 67 & $24 \cdot 5$ \\
50 & $7340^{\prime}$ & $27 \cdot 9$ \\
70 & 79 & $49 \cdot 3$ \\
\hline
\end{tabular}

I have not thought it necessary to follow out these results through so long a series of incidences as Mr. Potter has done; but for the purpose of the results here aimed at, I have no doubt these comparisons will be deemed sufficient. Here again my resulting ratios differ most widely from those of Mr. Potter; yet they will be found to give (for the case of perpendicular incidence) an agreement with theory, which is fully as exact as can be expected from experiments of this nature. The ratio from the undulatory theory as calculated by Mr. Potter, being in this case $18 \cdot 36$, by my experiments it is $20 \cdot 6$.

Another set of experiments, conducted and calculated precisely in the same way, gave me very similar results for a surface of glass of antimony.

\begin{tabular}{|c|c|c|}
\hline $\begin{array}{c}\text { Incidence on } \\
\text { Glass of } \\
\text { Antimony. }\end{array}$ & $\begin{array}{c}\text { Corresponding } \\
\text { Incidence on } \\
\text { Glass. }\end{array}$ & $\begin{array}{c}\text { Ratio of Reflection } \\
\text { by Formula. }\end{array}$ \\
\hline $0^{\circ}$ & $61^{\circ}$ & $16 \cdot 4$ \\
10 & 61 & $16 \cdot 6$ \\
50 & 66 & $17^{\circ}$ \\
80 & 80 & $36^{\circ}$ \\
\hline
\end{tabular}

For perpendicular incidence the undulatory theory gives the ratio 13.33 .

I have made other experiments with several substances, which I will not now detail, as my principal object is answered if I can draw attention to these results, so as to induce any one sufficiently versed in the subject to investigate the source of error, which somewhere and somehow has certainly crept in, to give rise to the remarkable discrepancy between my results and those of Mr. Potter. Our data of observation, it will be seen, agree in a singularly close manner, and the trifling errors of observation are such as can in no way account 
444 Mr. Faraday on the Magnetic Spark and Shock.

for the differences in our results. It seems only possible to account for it by some oversight in the calculations: but where it lies I am totally unable to say. I have given at large the principles on which my calculations are founded, which, I believe, are in a mathematical point of view correct. At any rate the subject eminently deserves further inquiry, which I bope and trust it may receive from those who are much better qualified than myself to do justice to it. Professional avocations have, indeed, hindered me from going into as accurate an examination of it as I could wish, and will, I fear, (for some time at least,) prevent me from entering upon a similar repetition of those other highly interesting photometrical researches, which relate to the reflection from metallic surfaces, in which Mr. Potter has found such curious anomalies. These, however, are not so immediately connected with the object I had in view, which chiefly refers to the controversy in regard to the undulatory theory. The experiments, however, on reflection from glass at different incidences have a stronger claim to attentive examination, as forming the basis of the calculation in all the other instances.

Queen Street, Nov. 1, 1834.

LXII. AdditionalObservations respecting the Magneto-electric Spark and Shock. By Michael Faraday, Esq., D.C.L., F.R.S., \&c.

To Richard Phillips, Esq., F.R.S., \&c.

My dear Sir,

I IKE most things done in haste, my letter to you last month involves several errors, some from want of attention, others from want of knowledge. Will you do me the favour to print the present in correction of them?

The first error consists in supposing the electricity of the shock and the electricity of the spark (obtained at the moment of disjunction) are due to different currents, page 351 . They are, as I find by careful experiments, due to the same current, namely, one produced by an inductive action at the moment when the current from the electromotor ceases.

If at p. 351, line 26, after "set in motion" be inserted " through the body ;" and at line 31 , for " counter" be read " second", and if the above statement be allowed to stand for that at the top of page 35\%, this error will be corrected.

The experimental results which I anticipated, page 352, lines 31-35, and page 354, lines 26-32, do not occur except under peculiar circumstances, and 1 am now aware why, for natural reasons, they should not. All the effects, in fact, 